\title{
Editorial
}

\section{Medical hypnosis and surgery, towards a new hermeneutic of care}

\author{
Vianney Descroix ${ }^{1,2, *}$ \\ ${ }^{1}$ Département de Biologie Orale UFR d'Odontologie Garancière Université de Paris, Paris, France \\ ${ }^{2}$ d'Odontologie Hôpital Pitié Salpêtrière APHP Sorbonne Université, Paris, France
}

(Received: 6 November 2020, accepted: 8 November 2020)

\section{Prolegomena: does hypnosis exist?}

It is clear that in France, as in the rest of the world, more and more of us are learning and practicing medical hypnosis. A consultation in the PubMed database with the Mesh term "hypnosis" allows 15,101 occurrences to be found. Since the 18th century, hypnosis has continued to accompany history, illustrating it with its multiple riches, whether medical, psychological, philosophical or anthropological. Despite all this, it is still and always legitimate to wonder about the existence of hypnosis and by extension its usefulness in medicine. So what is this hypnosis phenomenon whose name is the same in a performance hall as it is in an operating theater? Are we really sure that hypnosis exists? If we refer to high health authorities, learned societies or the National Academy of Medicine, medical hypnosis seems difficult to pin down. We take as proof the astonishing number of denominations to try - in vain - to categorize, even classify this approach. Depending on the interlocutors and the source, Assistance Publique - Hopitaux of Paris [1], National Academy of Medicine [2], National Council of the Order of Physicians [3], Inserm [4], Ministry of Solidarity and Health [5], hypnosis can alternately be medicine soft, natural medicine, alternative medicine, complementary medicine, supportive care or even an unconventional care practice (PSNC). The latter term is currently the one used by the Ministry of Health. Let us add that in France, there is currently no precise regulatory framework governing the modalities of the practice of hypnosis. However, this is considered a medical act, which even has its code in the CCAM nomenclature ("Hypnosis session for analgesia" ANRP001). This semantic proliferation is not without generating an administrative imbroglio, a sort of French folk bureaucracy, which raises and questions the question of the scientific and medical legitimacy of hypnosis in the practice of care.

\footnotetext{
*Correspondence: vianney.descroix@aphp.fr
}

\section{From the state to the hypnotic experience}

The definitions of medical hypnosis are multiple and multifaceted and, as we have seen, the word hypnosis is polysemic. It therefore appears essential and primordial to place the practice of hypnosis (1) in a context, here medicosurgical; and (2) with an intention, here that of a personcentered practice. It is in this context and with this intention that we speak here of medical hypnosis. This then differentiates it from so-called show hypnosis and hypnosis used in psychotherapy (hypnotherapy) or even in the context of personal development (hypnocoaching). Once the context and intention are set, we can define medical hypnosis along three axes.

(1) Hypnosis is a condition. Let us first look at the state in which the hypnotized person is. It is an altered state of consciousness characterized by an intense focus of attention. It is a question of a singular form of mental absorption associated with a relative suspension of peripheral consciousness. This state is, after all, quite ordinary and corresponds to this well-known state of concentration experienced in a pleasant task (reading) and / or routine (train travel). The hypnotic state is thus based on three components:

- Absorption, which is the tendency to become fully involved in a perceptual, imaginative or ideational experience;

- Dissociation, which corresponds to the mental separation of the components of the experience which would normally be treated together;

- Suggestibility, which is a reactivity to social signals, leading to an increased tendency to comply with hypnotic instructions, representing a suspension of critical judgment.

Finally, when some define hypnosis as a natural state, it is this state of absorption, of abandonment that we are talking about. An absorption which leads to a dissociation which allows greater suggestibility to the practitioner's proposals, which are the hypnotic suggestions. This state is also called 
hypnotic trance. It is this singular trance state which best characterizes the hypnotic state.

(2) Hypnosis is a process. The process of medical hypnosis is obviously unnatural and requires diligent experience, exercise and practice. In other words, it is a real journey, punctuated by different stages (such as induction for example) which allow one person (doctor, surgeon, nurse) to accompany another (the patient). in the hypnotic state. While in the operating room, the patient is lying on the table, that he is fully aware that he will benefit from a surgical intervention, that around him, the anesthetist, the surgeon, the IADE, the IBODE do what they have to do, we offer him to live an experience in hypnosis. After studying them, practicing the art of health communication, knowing the influence and rhetoric of hypnotic tools are helpful so that this person, in confidence, allows himself to be accompanied in the experience of hypnosis. This is why we consider hypnosis to be a meeting, a meeting to take care of and then it becomes a reciprocal influence [6]. Hypnosis is a process, it becomes what is played in two and between the two. Hypnosis is, as we have just seen, a special state.

(3) Hypnosis is an experience. What we call the phenomenology of hypnosis is concerned with the experiential nature of what the hypnotized person experiences on the order of the intimate. We must then study hypnosis from the perspective of the experimenting subject, through his or her own subjectivity. What most exactly characterizes the experience of hypnosis is a feeling of suspension of the will, the temporary loss of the feeling of self-agent, what is called agency. As Pierre Rainville and Donald Price suggest, hypnosis is associated with a feeling of automaticity which reflects a change in the representation of oneself as the causal agent of one's own responses [7]. This loss of will, associated with a feeling of being able to do without judgment or censorship, leads the person who experiences hypnosis to a mode of modified body consciousness and therefore a momentary and not final alteration of self-awareness, of the environment. and from oneself in interaction with the environment. This is the reason why the philosopher François Roustang speaks of hypnosis as an ecotherapy, that is to say a way of accessing another relationship to the world and therefore to anxiety, sedation or still the analgesia in the surgical indications which question us here.

\section{From evidence to indications}

Medical hypnosis has nothing to envy to other medical disciplines in terms of research, whether it is "fundamental" or clinical, whether it is the so-called instrumental hypnosis which makes it possible to access and study the modified states of consciousness or hypnosis as an issue for sedation and / or pain relief in the operating room [8]. Cognitive psychology, like neurosciences, today allows a precise reading of the neurophysiological issues of hypnosis [9]. Numerous studies have demonstrated the interest of hypnotic procedures in various clinical situations, such as pain management, treatment of phobia, depression, dissociative and psychotic disorders, etc [10]. To date, only two indications bring together sufficient qualitative and quantitative data to conclude that it is of therapeutic interest. These are the treatment of irritable bowel syndrome (functional bowel disease) and sedation / analgesia during surgery. This last indication interests us directly here. Hypnosis for analgesia or during anesthesia should be performed as part of conventional medical care and should not be a substitute for it. Hypnosis consists, in the context of certain surgeries, of combining hypnosis with local anesthesia and more or less with conscious sedation. Studies show improved intraoperative comfort, reduced anxiety and pain, decreased intraoperative need for anxiolytic and analgesic drugs, optimal surgical conditions as well as faster recovery for the patient. There are many indications for surgical procedures under local anesthesia and hypnosis, including oral surgery. The work of M.E. Faymonville in this area is exemplary. They have shown that hypnosis in addition to conscious intravenous sedation provides better perioperative pain and anxiety relief compared to simple intravenous sedation or a relaxation procedure. A recent metaanalysis comprising a total of 2597 patients undergoing surgical or medical interventions revealed effects of hypnosis on various pre and postoperative factors such as emotional distress, pain, drug use, physiological parameters, recovery and duration of surgery compared to the norm [11]. By applying the hypnotic procedure commonly used in surgery, the vast majority of authors show that the affective (inconvenience) and sensory (perceived intensity) components of pain perception are both reduced compared to control conditions, this is moreover. also demonstrated in oral surgery [12].

\section{To conclude}

Medical hypnosis is in turn a method, an approach, a state, an experience, a curiosity, an art, a talent, a skill, a philosophy. It offers a unique hermeneutics of care which, from a holistic perspective, considers the person as a whole and especially in their interaction with the environment. It asks those who practice it to be fully present in the treatment, intimately linked to the hypnotized person. It is only on this condition, in a "tailor-made" treatment that its results are spectacular, with anxiolytic and analgesic sedation. It involves adopting a necessary paradigm shift in the way medicine is practiced for those who, in order to feed their curiosity, take the trouble to take an interest in it.

\section{References}

1. Fagon JY. Médecines complémentaires à l'assistance publique, hôpitaux de Paris, 2012, available at: https://seronet.info/sites/ default/files/shared/admin/images/rapport_medecine_comple mentaire_ap-hp-2012.pdf

2. Bull. Acad. Natle. Mède.: Thérapie complémentaires, leurs places parmi les ressources de soins. 2013;197:717-757.

3. https://www.conseil-national.medecin.fr/sites/default/files/ex ternal-package/webzine/2015-07/www/index.html\#/page-4 
4. Gueguen J et al. Évaluation de l'efficacité de la pratique de l'hypnose. Inserm juin 2015.

5. https://solidarites-sante.gouv.fr/soins-et-maladies/qualite-dessoins-et-pratiques/securite/article/les-pratiques-de-soins-nonconventionnelles

6. Descroix V. L'hypnose médicale: une rencontre pour prendre soin. Revue d'Orthopédie Dento-Faciale 2020;54:13-21.

7. Rainville $P$, Price DD. Hypnosis phenomenology and the neurobiology of consciousness. Int J Clin Exp Hypn. 2003;51:105-129.

8. Jensen MP, et al. New directions in hypnosis research: strategies for advancing the cognitive and clinical neuroscience of hypnosis. Neurosci Conscious. 2017;3:004.
9. Terhune DB, Cleeremans A, Raz A, Lynn SJ. Hypnosis and topdown regulation of consciousness. Neurosci Biobehav Rev. 2017;81:59-74.

10. Vanhaudenhuyse A, Laureys S, Faymonville ME. Neurophysiology of hypnosis. Neurophysiol Clin. 2014;44:343-53.

11. Tefikow S, Barth J, Maichrowitz S, Beelmann A, Strauss B, Rosendahl J. Efficacy of hypnosis in adults undergoing surgery or medical procedures: a meta-analysis of randomized controlled trials. Clin Psychol Rev. 2013;33:623-36.

12. Mackey EF. Effects of hypnosis as an adjunct to intravenous sedation for third molar extraction: a randomized, blind, controlled study. Int J Clin Exp Hypn. 2010;58:21-38. 